OPEN ACCESS

Edited by:

Angel Lanas,

University of Zaragoza, Spain

Reviewed by:

Hiroshi Nakase,

Sapporo Medical University, Japan

Kunkai Su,

Zhejiang University, China

*Correspondence:

Gabriella Pár

pargabriella@gmail.com

${ }^{\dagger}$ These authors have contributed equally to this work

Specialty section

This article was submitted to

Gastroenterology,

a section of the journal

Frontiers in Medicine

Received: 12 June 2020 Accepted: 05 October 2020 Published: 13 November 2020

Citation:

Váncsa S, Hegyi PJ, Zádori N,

Szakó L, Vörhendi N, Ocskay K, Földi M, Dembrovszky F, Dömötör ZR,

Jánosi K, Rakonczay $Z \mathrm{~J} r$

Hartmann $P$, Horváth T, Eröss $B$,

Kiss $S$, Szakács Z, Németh D, Hegyi $P$ and Pár G (2020) Pre-existing Liver

Diseases and On-Admission Liver-Related Laboratory Tests in COVID-19: A Prognostic Accuracy Meta-Analysis With Systematic Review. Front. Med. 7:572115. doi: 10.3389/fmed.2020.572115

\section{Pre-existing Liver Diseases and On-Admission Liver-Related Laboratory Tests in COVID-19: A Prognostic Accuracy Meta-Analysis With Systematic Review}

\author{
Szilárd Váncsa ${ }^{1,2 \dagger}$, Péter Jeno Hegyi ${ }^{1 \dagger}$, Noémi Zádori ${ }^{1,2}$, Lajos Szakó ${ }^{1,2}$, Nóra Vörhendi ${ }^{1,2}$, \\ Klementina Ocskay ${ }^{1,2}$, Mária Földi ${ }^{1,2,3}$, Fanni Dembrovszky ${ }^{1,2}$, Zsuzsa Réka Dömötör ${ }^{4}$, \\ Kristóf Jánosi ${ }^{5}$, Zoltán Rakonczay Jr. ${ }^{6}$, Petra Hartmann ${ }^{7}$, Tamara Horváth ${ }^{7}$, Bálint Eröss ${ }^{1}$, \\ Szabolcs Kiss ${ }^{1,2,3}$, Zsolt Szakács ${ }^{1,2}$, Dávid Németh ${ }^{1}$, Péter Hegyi ${ }^{1,2}$ and Gabriella Pár ${ }^{8 *}$ \\ on behalf of the KETLAK Study Group \\ ${ }^{1}$ Institute for Translational Medicine, Medical School, University of Pécs, Pécs, Hungary, ${ }^{2}$ János Szentágothai Research \\ Center, University of Pécs, Pécs, Hungary, ${ }^{3}$ Doctoral School of Clinical Medicine, University of Szeged, Szeged, Hungary, \\ ${ }^{4}$ Faculty of Medicine, George Emil Palade University of Medicine, Pharmacy, Science and Technology of Târgu Mureş, Târgu \\ Mureş, Romania, ${ }^{5}$ Heart Institute, Medical School, University of Pécs, Pécs, Hungary, ${ }^{6}$ Department of Pathophysiology, \\ University of Szeged, Szeged, Hungary, ${ }^{7}$ Institute of Surgical Research, University of Szeged, Szeged, Hungary, ${ }^{8}$ Division of \\ Gastroenterology, First Department of Medicine, Medical School, University of Pécs, Pécs, Hungary
}

Background: We aimed to perform a systematic search and meta-analysis to evaluate the prognostic value of on-admission liver function tests and pre-existing liver diseases on the clinical course of coronavirus disease 2019 (COVID-19).

Methods: The study was registered on PROSPERO (CRD42020182902). We searched five databases between 01/01/2020 and 04/23/2020. Studies that reported on liver-related comorbidities and/or laboratory parameters in patients with COVID-19 were included. The main outcomes were COVID-19 severity, intensive care unit (ICU) admission, and in-hospital mortality. Analysis of predictive models hierarchical summary receiver-operating characteristic (HSROC) was conducted with a 95\% confidence interval $(\mathrm{Cl})$.

Results: Fifty studies were included in the meta-analysis. High specificity was reached by acute liver failure associated by COVID-19 (0.94, 95\% Cl: 0.71-0.99) and platelet count $(0.94,95 \% \mathrm{Cl}: 0.71-0.99)$ in the case of mortality; chronic liver disease (CLD) (0.98, 95\% Cl: 0.96-0.99) and platelet count (0.82, 95\% Cl: 0.72-0.89) in the case of ICU requirement; and $\operatorname{CLD}(0.97,95 \% \mathrm{Cl}$ : 0.95-0.98), chronic hepatitis B infection $(0.97,95 \%$ $\mathrm{Cl}$ : 0.95-0.98), platelet count (0.86, 95\% Cl: 0.77-0.91), and alanine aminotransferase (ALT) (0.80, 95\% Cl: 0.66-0.89) and aspartate aminotransferase (AST) $(0.84,95 \% \mathrm{Cl}$ : $0.77-0.88$ ) activities considering severe COVID-19. High sensitivity was found in the case of C-reactive protein (CRP) for ICU requirement (0.92, 95\% Cl: 0.80-0.97) and severe COVID-19 (0.91, 95\% Cl: 0.82-0.96).

Conclusion: On-admission platelet count, ALT and AST activities, CRP concentration, and the presence of acute and CLDs predicted the severe course of COVID-19. To 
highlight, pre-existing liver diseases or acute liver injury associated by severe acute respiratory syndrome coronavirus 2 (SARS-CoV-2) infection plays an important role in the prediction of mortality.

Keywords: SARS-CoV-2, COVID-19, prognosis, hepatology, pandemic (COVID-19)

\section{INTRODUCTION}

In December 2019, a local outbreak of pneumonia caused by a novel coronavirus, namely, severe acute respiratory syndrome coronavirus 2 (SARS-CoV-2), was detected in Wuhan, China. In most cases, coronavirus disease 2019 (COVID-19) is an acute, self-limiting disease with a relatively brief period of symptoms and resolution within days. However, it can reach in-hospital mortality of $3-7 \%$ (1), which can result from massive alveolar damage, consequential acute respiratory distress syndrome (ARDS), respiratory failure, septic shock, or multiple organ dysfunction $(2,3)$.

It is important to explore the prognostic factors, which have a significant impact on the disease course, given the rapid spread of COVID-19 and its high mortality rate. The detrimental effects of hypertension, cardiovascular diseases, kidney disease, and diabetes mellitus on the disease course are already proven (46). Due to the limited number of reports on COVID-19 with underlying chronic liver disease (CLD) to date, the impact of pre-existing liver pathologies on COVID-19 progression and outcomes is unknown.

Although coronaviruses cause the worst damage on the lungs, studies suggest that other organs, such as the liver, intestines, heart, and central nervous system, could also be affected (711). In COVID-19, almost half of the hospitalized patients have various degrees of liver test abnormalities, and liver impairment was also observed in $14-53 \%$ of the patients (12).

We aimed to appraise the currently available literature of confirmed SARS-CoV-2 infections critically and to investigate the prognostic value of on-admission liver function and liver conditions on the clinical course of COVID-19.

\section{MATERIALS AND METHODS}

Our systematic review and meta-analysis was planned and reported according to the PRISMA (Preferred Reporting Items for Systematic Reviews and Meta-Analyses) 2009 Statement (13) (Supplementary Table 1). This study was registered in advance on PROSPERO under registration number CRD42020182902 (see https://www.crd.york.ac.uk/prospero).

\section{Search and Selection}

A systematic search was conducted by two independent reviewers (LS and NZ) to identify all the relevant records on the prognostic value of liver impairment in COVID-19 patients published from January 1, 2020 to April 23, 2020. The search was performed in MEDLINE via PubMed, Embase, Scopus, Cochrane Library, and Web of Science with the terms ("covid 19") OR ("Wuhan virus") OR (“coronavirus") OR (“2019 nCoV”) OR (“SARS-CoV-2”) without language or other restrictions. References were managed by the EndNote X9 software (Clarivate Analytics, Philadelphia, PA, USA). Following the removal of duplicates, title and abstract screening were performed by two independent reviewers $(\mathrm{PJH}$ and NV) to identify potentially eligible articles. Disagreements were reviewed by a third review author (KJ) and resolved by consensus. The reference lists of the relevant articles were handsearched, and additional eligible records were included.

We included studies without any restriction that reported on $(C)$ liver diseases (as defined by eligible studies) and/or onadmission liver function tests in $(P)$ patients with confirmed COVID-19. Concerning the laboratory parameters, cut-off values predefined by the individual studies were used for abnormal parameters $(O)$. The assessed outcomes were as follows: inhospital mortality, severe SARS-CoV-2 infection defined by eligible studies, and intensive care unit (ICU) requirement defined by eligible studies. Severity of COVID-19 was classified according to the guidelines on the Diagnosis and Treatment of COVID-19 issued by the National Health Commission of China (14). Details are presented in Supplementary Table 2. Studies with a sample size of fewer than 15 subjects were excluded because of the small effect size. When there were multiple publications using data with overlapping study populations, we included the one with a greater sample size.

\section{Data Extraction and Outcomes}

Relevant data were independently extracted from studies by review authors ZRD and FD. These included: first author, year of publication, country of origin, time interval and place of the study, study design, basic characteristics of the study population (age, percentage of females, and size of the study groups), the proportion of event (in-hospital mortality, severe SARSCoV-2 infection, and need for ICU care) in patients with and without liver impairment, time of measurement for outcomes, and serum laboratory parameters [total bilirubin, albumin, aspartate aminotransferase (AST), alanine aminotransferase (ALT), alkaline phosphatase (ALP), gamma-glutamyl transferase (GGT), platelet count, international normalized ratio (INR), lactate dehydrogenase ( $\mathrm{LDH})$, and C-reactive protein (CRP)], predefined cut-off values, and information for risk of bias assessment. Extracted data were validated by MF and SK.

\section{Statistical Analysis}

Calculations were performed by Stata 15 data analysis and statistical software (StataCorp LLC, College Station, TX, USA). The first preference was the analysis of hierarchical summary receiver-operating characteristic (HSROC) predictive models with 95\% confidence interval (CI) when at least five articles were available for the given outcome. The area under the curve (AUC) values and their 95\% CIs for each prognostic factor and outcome were collected, and a meta-analysis using the random 

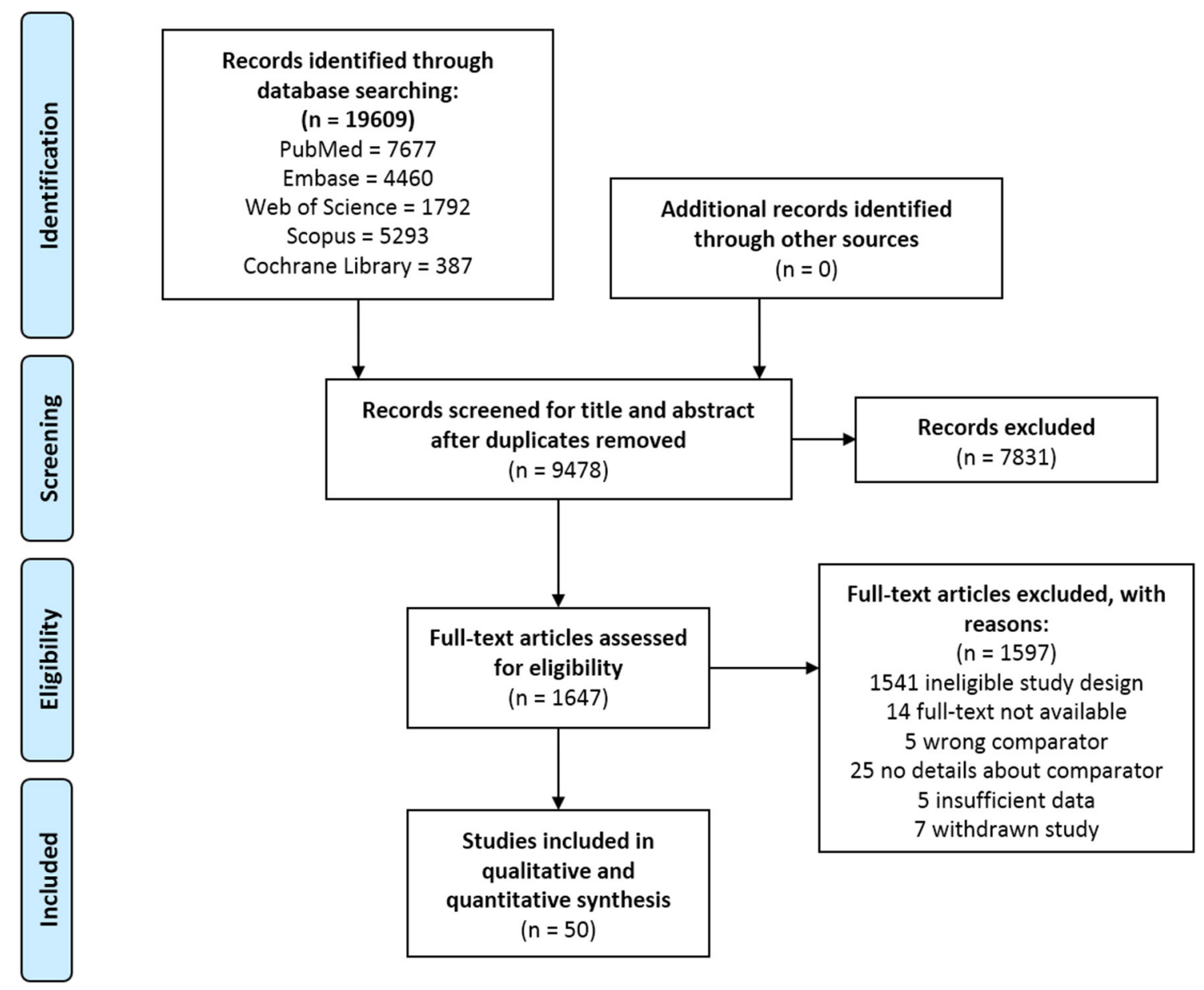

FIGURE 1 | PRISMA flowchart.

effect model to gain pooled AUC estimates with 95\% CI was performed. Second preference in case of dichotomous variables (mortality, severe vs non-severe, and ICU vs. non-ICU) was the calculation of odds ratios (OR) with a $95 \%$ CI. A $p<0.05$ was considered statistically significant.

Heterogeneity was tested with $I^{2}$ and $\chi^{2}$ tests. As suggested by the Cochrane Handbook, $I^{2}$ values were interpreted as moderate (30-60\%), substantial (50-90\%), and considerable (75-100\%) heterogeneity (15). A $p<0.10$ was considered significant. Forest plots and HSROC curves were used to present the results of the meta-analyses. Publication bias was checked by Egger's test (alpha $=0.1$ ) when at least 10 studies were available (16). A $p<0.1$ was chosen because of the low number of studies included in our analyses, since it can determine a significant heterogeneity with greater certainty (17).

\section{Assessment of Risk of Bias}

Bias assessment was performed by two authors independently (PHa and TH) using the modified Quality In Prognosis Studies (QUIPS) assessment tool (18). Disagreements were resolved by a third investigator (GP). Details of the used QUIPS tool are shown in the footnote of Supplementary Table 5.

\section{Protocol Deviation}

We waived the need for data extraction and analysis regarding the continuous variables and Funnel plots after statistical consultation as it did not provide additional value.

\section{RESULTS}

Overall, 19,609 records were identified through the comprehensive search, from which 1,647 full texts were reviewed, and 50 studies were included in the qualitative and quantitative syntheses. The selection process is presented in Figure 1.

Basic characteristics of the included studies are shown in Table 1 and Supplementary Table 3. Detailed eligibility criteria for each included study are presented in Supplementary Table 4. 
TABLE 1 | Basic characteristics of the included studies.

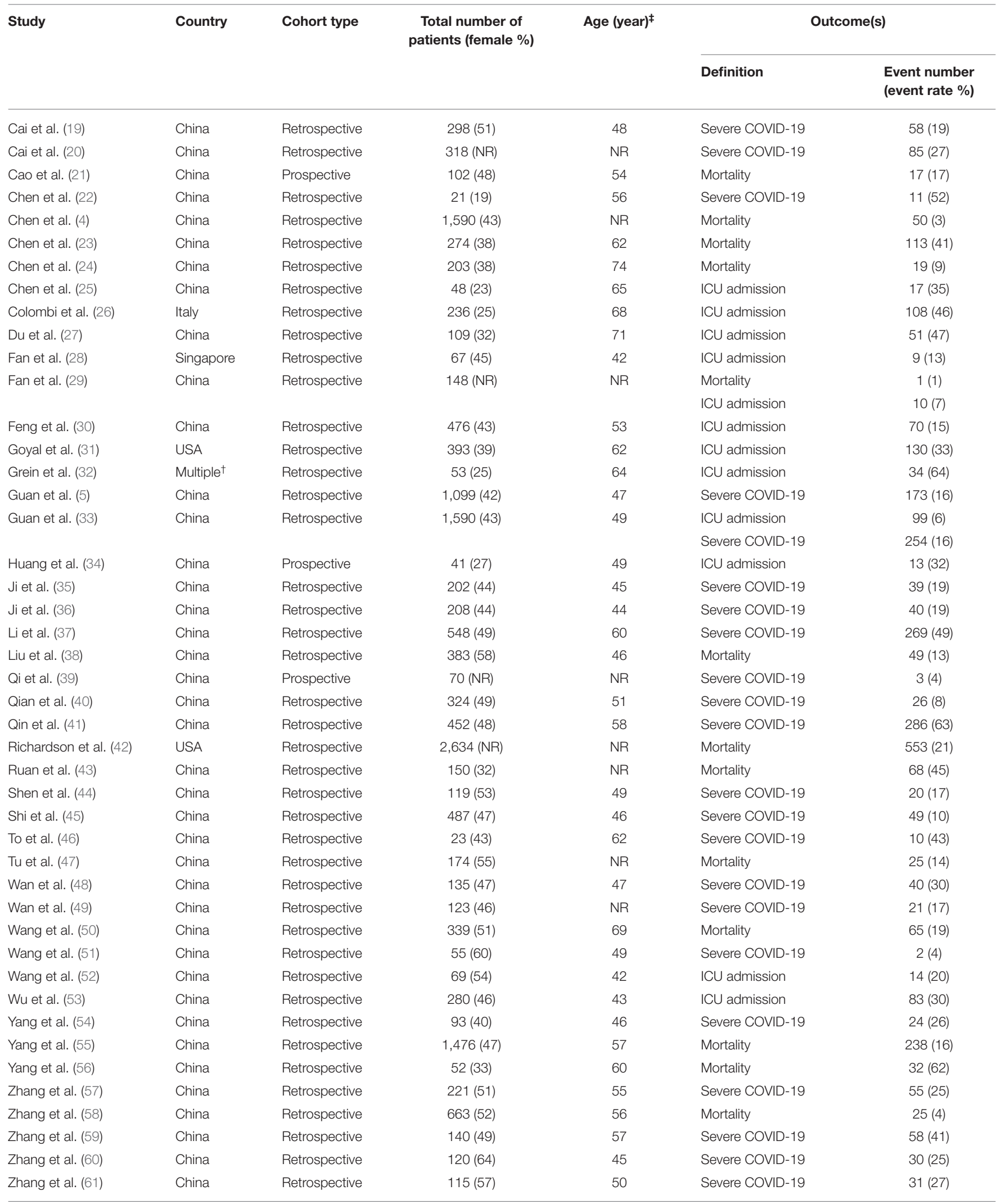


TABLE 1 | Continued

\begin{tabular}{|c|c|c|c|c|c|c|}
\hline \multirow[t]{2}{*}{ Study } & \multirow[t]{2}{*}{ Country } & \multirow[t]{2}{*}{ Cohort type } & \multirow{2}{*}{$\begin{array}{c}\text { Total number of } \\
\text { patients (female \%) }\end{array}$} & \multirow[t]{2}{*}{ Age (year) $)^{\ddagger}$} & \multicolumn{2}{|c|}{ Outcome(s) } \\
\hline & & & & & Definition & $\begin{array}{l}\text { Event number } \\
\text { (event rate \%) }\end{array}$ \\
\hline Zheng et al. (62) & China & Retrospective & $161(50)$ & 45 & Severe COVID-19 & 30 (19) \\
\hline Zheng et al. (63) & China & Retrospective & $96(40)$ & 55 & Severe COVID-19 & $74(77)$ \\
\hline Zhou et al. (64) & China & Retrospective & $191(38)$ & 56 & Mortality & $54(28)$ \\
\hline Zhou et al. (65) & China & Retrospective & $15(33)$ & 62 & Mortality & $7(47)$ \\
\hline Zhou et al. (66) & China & Retrospective & $21(38)$ & 66 & ICU admission & $13(62)$ \\
\hline
\end{tabular}

COVID-19, coronavirus disease 2019; ICU, intensive care unit admission; NR, not reported.

${ }^{\dagger}$ Multiple countries (USA, Japan, Italy, Austria, France, Germany, Netherlands, Spain, and Canada); ${ }^{\ddagger}$ mean or median.

TABLE 2 | Summary table of mortality, severe COVID-19, and intensive care unit requirement based on the HSROC analysis.

\begin{tabular}{|c|c|c|c|c|c|c|c|c|c|c|}
\hline Prognostic factor & $\begin{array}{c}\text { No. of } \\
\text { studies } \\
\text { (no. of cases) }\end{array}$ & $\begin{array}{c}\text { AUC } \\
(95 \% \mathrm{Cl})\end{array}$ & $\begin{array}{c}\text { Sensitivity } \\
\text { (95\% Cl) }\end{array}$ & $I^{2}(\%)$ & $\mathrm{Chi}^{2}$ & $\begin{array}{c}\text { Specificity } \\
\text { (95\% Cl) }\end{array}$ & $I^{2}(\%)$ & $\mathrm{Chi}^{2}$ & $\begin{array}{c}\text { PLR } \\
(95 \% \mathrm{Cl})\end{array}$ & $\begin{array}{c}\text { NLR } \\
(95 \% \mathrm{Cl})\end{array}$ \\
\hline \multicolumn{11}{|l|}{ Mortality } \\
\hline Liver failure & $5(3,523)$ & $0.67(0.63-0.71)$ & $0.31(0.12-0.59)$ & 99 & 0.001 & $0.94(0.71-0.99)$ & 99 & 0.001 & $5.5(1.6-19.4)$ & $0.73(0.55-0.97)$ \\
\hline Platelet count & $5(3,259)$ & $0.71(0.67-0.75)$ & $0.40(0.23-0.59)$ & 95 & 0.001 & $0.89(0.75-0.96)$ & 99 & 0.001 & $3.7(1.5-9)$ & $0.68(0.5-0.91)$ \\
\hline ALT & $5(2,127)$ & $0.76(0.72-0.79)$ & $0.41(0.30-0.53)$ & 71 & 0.01 & $0.77(0.75-0.80)$ & 0 & 0.63 & $1.8(1.4-2.4)$ & $0.76(0.64-0.92)$ \\
\hline $\mathrm{LDH}$ & $5(2,149)$ & $0.81(0.78-0.85)$ & $0.87(0.74-0.94)$ & 71 & 0.01 & $0.58(0.41-0.73)$ & 95 & 0.001 & $2.1(1.4-3.1)$ & $0.22(0.1-0.48)$ \\
\hline \multicolumn{11}{|c|}{ Intensive care unit requirement } \\
\hline Chronic liver disease & $5(831)$ & $0.80(0.77-0.84)$ & $0.03(0.01-0.06)$ & 0 & 0.48 & $0.98(0.96-0.99)$ & 59 & 0.04 & $1.3(0.5-3.3)$ & $0.99(0.97-1.02)$ \\
\hline Platelet count & $5(628)$ & $0.47(0.43-0.52)$ & $0.18(0.11-0.28)$ & 35 & 0.19 & $0.82(0.72-0.89)$ & 63 & 0.03 & $1(0.6-1.6)$ & $1(0.9-1.12)$ \\
\hline ALT & $5(1,190)$ & $0.58(0.54-0.62)$ & $0.32(0.25-0.41)$ & 33 & 0.20 & $0.76(0.70-0.81)$ & 52 & 0.08 & $1.3(1.1-1.7)$ & $0.89(0.81-0.98)$ \\
\hline AST & $6(1,229)$ & 0.65 (0.61-0.69) & $0.55(0.47-0.62)$ & 37 & 0.16 & $0.69(0.62-0.75)$ & 78 & 0.001 & $1.7(1.5-2.1)$ & $0.66(0.57-0.76)$ \\
\hline CRP & $6(1,412)$ & $0.75(0.72-0.79)$ & $0.92(0.80-0.97)$ & 88 & 0.001 & $0.31(0.14-0.54)$ & 95 & 0.001 & $1.3(1.1-1.7)$ & $0.27(0.16-0.46)$ \\
\hline \multicolumn{11}{|l|}{ Severe COVID-19 } \\
\hline Chronic liver disease & $10(2,182)$ & 0.65 (0.60-0.69) & $0.03(0.02-0.07)$ & 75 & 0.001 & 0.97 (0.95-0.98) & 76 & 0.001 & $1.2(0.6-2.1)$ & $1(0.97-1.02)$ \\
\hline Chronic hepatitis B & $7(3,911)$ & $0.71(0.67-0.75)$ & $0.03(0.01-0.08)$ & 84 & 0.001 & $0.97(0.95-0.98)$ & 85 & 0.001 & $1.2(0.6-2.4)$ & $1(0.97-1.02)$ \\
\hline Platelet count & $7(1,868)$ & $0.66(0.62-0.70)$ & $0.26(0.15-0.42)$ & 88 & 0.001 & $0.86(0.77-0.91)$ & 92 & 0.001 & $1.8(1.2-2.7)$ & $0.86(0.75-0.99)$ \\
\hline ALT & $8(1,625)$ & $0.60(0.55-0.64)$ & $0.31(0.19-0.48)$ & 94 & 0.001 & $0.80(0.66-0.89)$ & 96 & 0.001 & $1.6(1.1-2.2)$ & $0.86(0.74-0.99)$ \\
\hline AST & $9(2,780)$ & $0.70(0.65-0.74)$ & $0.40(0.30-0.50)$ & 88 & 0.001 & $0.84(0.77-0.88)$ & 90 & 0.001 & $2.4(1.8-3.2)$ & $0.72(0.63-0.83)$ \\
\hline $\mathrm{LDH}$ & $9(2,500)$ & $0.75(0.71-0.79)$ & $0.67(0.57-0.77)$ & 93 & 0.001 & $0.72(0.62-0.80)$ & 95 & 0.001 & $2.4(1.8-3.1)$ & $0.45(0.35-0.58)$ \\
\hline CRP & $6(2,253)$ & $0.68(0.64-0.72)$ & $0.91(0.82-0.96)$ & 89 & 0.001 & $0.34(0.23-0.47)$ & 94 & 0.001 & $1.4(1.2-1.5)$ & $0.27(0.18-0.42)$ \\
\hline
\end{tabular}

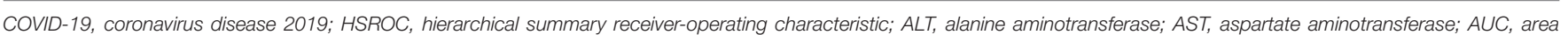
under the curve; Cl, confidence interval; CRP, C-reactive protein; $I^{2}$ and Chi², heterogeneity; LDH, lactate dehydrogenase; NLR, negative likelihood ratio; PLR, positive likelihood ratio.

\section{Diagnostic Metrics}

For the prediction of mortality, a high specificity was reached by liver failure (specificity: 0.94, 95\% CI: 0.71-0.99) and platelet count (specificity: 0.94, 95\% CI: 0.71-0.99) and a moderate sensitivity by LDH (sensitivity: 0.81, 95\% CI: 0.78-0.85).

For the prediction of possible ICU requirement, CLD (specificity: 0.98, 95\% CI: 0.96-0.99) and platelet count (specificity: $0.82,95 \%$ CI: $0.72-0.89$ ) proved to be specific, whereas CRP was associated with high sensitivity (sensitivity: 0.92, 95\% CI: 0.80-0.97).

For the prediction of severe disease course, CLD (specificity: 0.97, 95\% CI: 0.95-0.98) and chronic hepatitis B infection (specificity: $0.97,95 \%$ CI: $0.95-0.98$ ) were highly specific, and platelet count (specificity: $0.86,95 \%$ CI: $0.77-0.91$ ), ALT (specificity: 0.80, 95\% CI: 0.66-0.89), and AST (specificity: 0.84 , 95\% CI: $0.77-0.88$ ) were moderately specific, whereas high sensitivity was reached by CRP (sensitivity: 0.91, 95\% CI: 0.82-0.96).

CLD for mortality and total bilirubin in case of severe COVID-19 could not be analyzed because it was not feasible despite the number of included studies.

Detailed results about the AUC, sensitivity, specificity, likelihood ratios, and heterogeneity are shown in Table 2. The HSROC curves are summarized in Supplementary Figures 1-3. 


\section{Analysis of the Strength of the Association}

Liver failure (OR: 7.59; 95\% CI: 1.84-31.30), platelet count (OR: 5.36; 95\% CI: 1.28-22.37), albumin level (OR: 6.32; 95\% CI: 1.4028.60), and ALT (OR: 2.49; 95\% CI: 1.75-3.56), AST (OR: 5.39; 95\% CI: 3.67-7.91), and LDH (OR: 9.23; 95\% CI: 2.56-33.31) activities were related to a high rate of mortality. CLD, hepatitis $B$ infection, and CRP concentration did not show significant difference, considering mortality.

Albumin (OR: 3.79; 95\% CI: 2.08-6.93), ALT (OR: 1.56; 95\% CI: 1.61-2.11), AST (OR: 2.53; 95\% CI: 1.92-3.35), and LDH (OR: 7.95; 95\% CI: 4.54-13.92) levels and CRP (OR: 4.72; 95\% CI: 2.59-8.58) concentration were accompanied with high rate of ICU admission. A significant difference could not be stated regarding the need for ICU considering CLD, liver dysfunction, and platelet count.

Fatty liver disease (OR: 3.86; 95\% CI: 1.20-12.47), liver failure (OR: 3.27; 95\% CI: 1.20-8.87), total bilirubin (OR: 1.89; 95\% CI: 1.35-2.63), platelet count (OR: 2.34 ; 95\% CI: 1.53-3.58), albumin level (OR: 3.11; 95\% CI: 1.61-6.01), ALT (OR: 1.82; 95\% CI: 1.18-2.81), AST (OR: 3.34; 95\% CI: 2.37-4.71), LDH (OR: 5.02; 95\% CI: 3.41-7.40), CRP (OR: 4.52; 95\% CI: 3.16-6.49), and GGT (OR: 3.03; 95\% CI: 1.60-5.7) were accompanied with a higher risk for more severe course. CLD, hepatitis B infection, and elevated level of ALP did not show significant difference concerning severity.

Results of the analysis of association and heterogeneity are presented in Table 3. Forest plots for each analysis are shown in Supplementary Figures 4-17.

\section{Risk of Bias Assessment}

Results of the risk of bias assessment between studies are shown in Supplementary Table 5.

The assessment of publication bias could only be performed in the case of CLD on severe COVID-19. It did not suggest the presence of publication bias $(p=0.764)$.

\section{DISCUSSION}

This meta-analysis aimed to investigate the association between pre-existing liver diseases and on-admission liver functions and outcomes in COVID-19 infection, focusing on mortality, ICU admission, and severe disease course (Figure 2). Considering the prediction of mortality, liver failure and platelet count are highly specific, whereas LDH is moderately sensitive. For the prediction of ICU requirement, CLD was associated with high specificity, platelet count with moderate specificity, and CRP with high sensitivity. Regarding severe disease course, CLD and chronic hepatitis B infection were proven to be highly specific, and platelet count and ALT and AST activities were moderately specific, whereas CRP was highly sensitive.

In relation to the investigated factors and poorer outcomes, acute liver failure; platelet count; albumin level; ALT, AST, and $\mathrm{LDH}$ activities; and CRP concentration were associated with higher mortality. Albumin, ALT, AST, LDH, and CRP influenced the admission to the ICU. Fatty liver disease, liver injury, total bilirubin, ALT, AST, LDH, CRP, GGT, platelet count, and albumin level were associated with more severe disease course.
The knowledge about the impact of liver-related comorbidities in the clinical outcome of COVID-19 is limited. In line with our results, an earlier meta-analysis concluded that CLD is not associated with severity or mortality (67). However, clinicians should be skeptical about it, because these patients are more prone to infection due to cirrhosis-associated immune dysfunction and are more likely to have poor outcomes from ARDS $(68,69)$. This may account for the relatively low baseline prevalence of CLD in the included patients, as one previous meta-analysis suggests (70), or it was not well-reported. Further on, in a recently published letter on the involvement of the liver in COVID-19, the authors found an increased odds of severe infection and mortality in patients with liver injury (71). Another study analyzed the frequency of abnormal liver function derangements in severe COVID-19 and concluded that hypoalbuminemia followed by derangements in GGT and aminotransferases were more frequent in severe disease (72). On the other hand, another study highlights that digestive symptoms and liver injury are not uncommon in patients with SARS-CoV-2 infection (73).

Dysregulated hepatic immune responses caused by metabolic associated fatty liver disease (MAFLD) may contribute to cytokine storm in younger patients (74), whereas chronic low grade inflammation known to be associated with MAFLD may worsen outcome. Post-mortem liver biopsy showed overactivation of $\mathrm{T}$ cells in the liver, and liver injury is likely mediated by immune response rather than direct cytopathic damage (35).

Compared with previous results $(12,75,76)$, our study reasserts that in severe forms of COVID-19, alterations of onadmission level of the liver enzymes can be observed, probably due to the virally induced cytotoxic $\mathrm{T}$ cells and the innate immune response against the virus. Another reason behind the liver test abnormalities in COVID-19 patients could be the cholangiocyte dysfunction due to direct infection of bile duct cells via angiotensin-converting enzyme 2 receptor (8). However, according to our results, ALP does not seem to be a significant predictive marker in COVID-19. Additionally, moderate microvesicular steatosis, mild lobular, and portal activity can be observed in the pathological samples of patients who died from COVID-19 (77).

Despite the lack of coagulation factors in liver diseases, a hypercoagulable state could also be present in COVID19. A recent study concluded that COVID-19 disease has prominent manifestations from the hematopoietic system and is often associated with a major blood hypercoagulability (78). In histopathological findings, it was highlighted that extensive vascular portal and sinusoidal thrombosis could lead to abnormal high level of transaminases (79).

Considering the strengths of our meta-analysis, a rigorous methodology was followed. To our knowledge, this is the first study that addresses the prognostic value of on-admission liver parameters, underlying liver comorbidities, and COVID19 induced hepatic failure on the level of sensitivity and specificity. On the other hand, our study has several limitations. We only included cohort studies that mostly originate from Asia, which might carry a high risk of bias. The definitions 
TABLE 3 | Summary of findings.

\begin{tabular}{|c|c|c|c|c|c|c|c|c|c|c|c|c|}
\hline \multirow[t]{2}{*}{ Prognostic factor } & \multicolumn{4}{|c|}{ Mortality } & \multicolumn{4}{|c|}{ Intensive care unit requirement } & \multicolumn{4}{|c|}{ Severe COVID-19 } \\
\hline & $\begin{array}{l}\text { No. of studies } \\
\text { (no. of pts) }\end{array}$ & $\begin{array}{l}\text { Odds ratio } \\
(95 \% \mathrm{Cl})\end{array}$ & $I^{2}(\%)$ & $\mathrm{Chi}^{2}$ & $\begin{array}{l}\text { No. of studies } \\
\text { (no. of pts) }\end{array}$ & $\begin{array}{l}\text { Odds ratio } \\
(95 \% \mathrm{Cl})\end{array}$ & $I^{2}(\%)$ & $\mathrm{Chi}^{2}$ & $\begin{array}{l}\text { No. of studies } \\
\text { (no. of pts) }\end{array}$ & $\begin{array}{l}\text { Odds ratio } \\
(95 \% \mathrm{Cl})\end{array}$ & $I^{2}(\%)$ & $\mathrm{Chi}^{2}$ \\
\hline Chronic liver disease & $4(646)^{\dagger}$ & $1.5(0.42-5.41)$ & 0 & 0.54 & $5(831)$ & $1.42(0.56-3.63)$ & 0 & 0.72 & $10(2,182)$ & $1.45(0.87-2.42)$ & 0 & 0.7 \\
\hline Liver dysfunction & $2(145)$ & $1.13(0.36-3.58)$ & 0 & 0.33 & $2(384)$ & $1.77(0.62-5.06)$ & 0 & 0.98 & $2(163)$ & $1.11(0.36-3.47)$ & 0 & 0.56 \\
\hline Chronic hepatitis B & $2(1,864)$ & $1.18(0.42-3.34)$ & 0 & 0.97 & $1(1,590)$ & $0.55(0.07-4.11)$ & NR & NR & $7(3,911)$ & $1,55(0.85-2.83)$ & 13 & 0.33 \\
\hline Fatty liver disease & $N R$ & NR & $N R$ & NR & NR & NR & NR & $N R$ & $4(964)$ & $3.86(1.2-12.47)^{\star}$ & 79 & 0 \\
\hline Liver failure & $5(3,523)$ & $7.59(1.84-31.30)^{\star}$ & 91 & 0 & $1(43)$ & $1.88(0.47-7.54)$ & NR & NR & $4(1,185)$ & $3.27(1.2-8.87)^{\star}$ & 70 & 0.02 \\
\hline Total bilirubin & $1(975)$ & $5(2.48-10.07)^{\star}$ & NR & NR & 2 (395) & $1.66(0.45-6.06)$ & 33 & 0.22 & $6(2,059)$ & $1.89(1.35-2.63)^{\star}$ & 0 & 0.57 \\
\hline Platelet count & $5(3,259)$ & $5.36(1.28-22.37)^{\star}$ & 95 & 0 & $5(628)$ & $0.95(0.63-1.44)$ & 0 & 0.79 & $7(1,868)$ & $2.34(1.53-3.58)^{\star}$ & 46 & 0.09 \\
\hline International normalized ratio & NR & NR & NR & NR & $1(20)$ & $5(0.18-139.17)$ & NR & NR & $1(115)$ & $0.72(0.31-1.66)$ & NR & NR \\
\hline Albumin & $3(944)$ & $6.32(1.4-28.6)^{\star}$ & 63 & 0.07 & $3(744)$ & $3.79(2.08-6.93)^{\star}$ & 0 & 0.81 & $4(1,205)$ & $3.11(1.61-6.01)^{\star}$ & 69 & 0.02 \\
\hline Alanine aminotransferase & $5(2,127)$ & $2.49(1.75-3.56)^{\star}$ & 10 & 0.35 & $5(1,190)$ & $1.56(1.16-2.11)^{\star}$ & 0 & 0.99 & $8(1,625)$ & $1.82(1.18-2.81)^{\star}$ & 70 & 0 \\
\hline Aspartate aminotransferase & $4(1,966)$ & $5.39(3.67-7.91)^{\star}$ & 0 & 0.63 & $6(1,229)$ & $2.53(1.92-3.35)^{\star}$ & 0 & 0.48 & $9(2,780)$ & $3.34(2.37-4.71)^{\star}$ & 60 & 0.01 \\
\hline Lactate dehydrogenase & $5(2,149)$ & $9.23(2.56-33.31)^{\star}$ & 85 & 0 & $4(748)$ & $7.95(4.54-13.92)^{\star}$ & 0 & 0.75 & $9(2,500)$ & $5.02(3.41-7.4)^{\star}$ & 66 & 0 \\
\hline C-reactive protein & $4(1,846)$ & $9.19(0.84-100.63)$ & 77 & 0 & $6(1,412)$ & $4.72(2.59-8.58)^{\star}$ & 35 & 0.17 & $6(2,253)$ & $f 4.52(3.16-6.49)^{\star}$ & 31 & 0.21 \\
\hline Alkaline phosphatase & NR & NR & NR & NR & $1(19)$ & $0.11(0-2.73)$ & NR & NR & $4(623)$ & $1.71(0.66-4.46)$ & 24 & 0.27 \\
\hline Gamma-glutamyl transferase & NR & NR & NR & NR & $1(19)$ & $1.39(0.22-8.92)$ & NR & NR & $3(635)$ & $3.03(1.6-5.72)^{\star}$ & 50 & 0.14 \\
\hline
\end{tabular}

Cl, confidence interval; COVID-19, coronavirus disease 2019; $l^{2}$ and $C h i^{2}$, heterogeneity; NR, not reported.

${ }^{*} p<0.05{ }^{\dagger}$ one study could not be included in the analysis, because there were no events. 


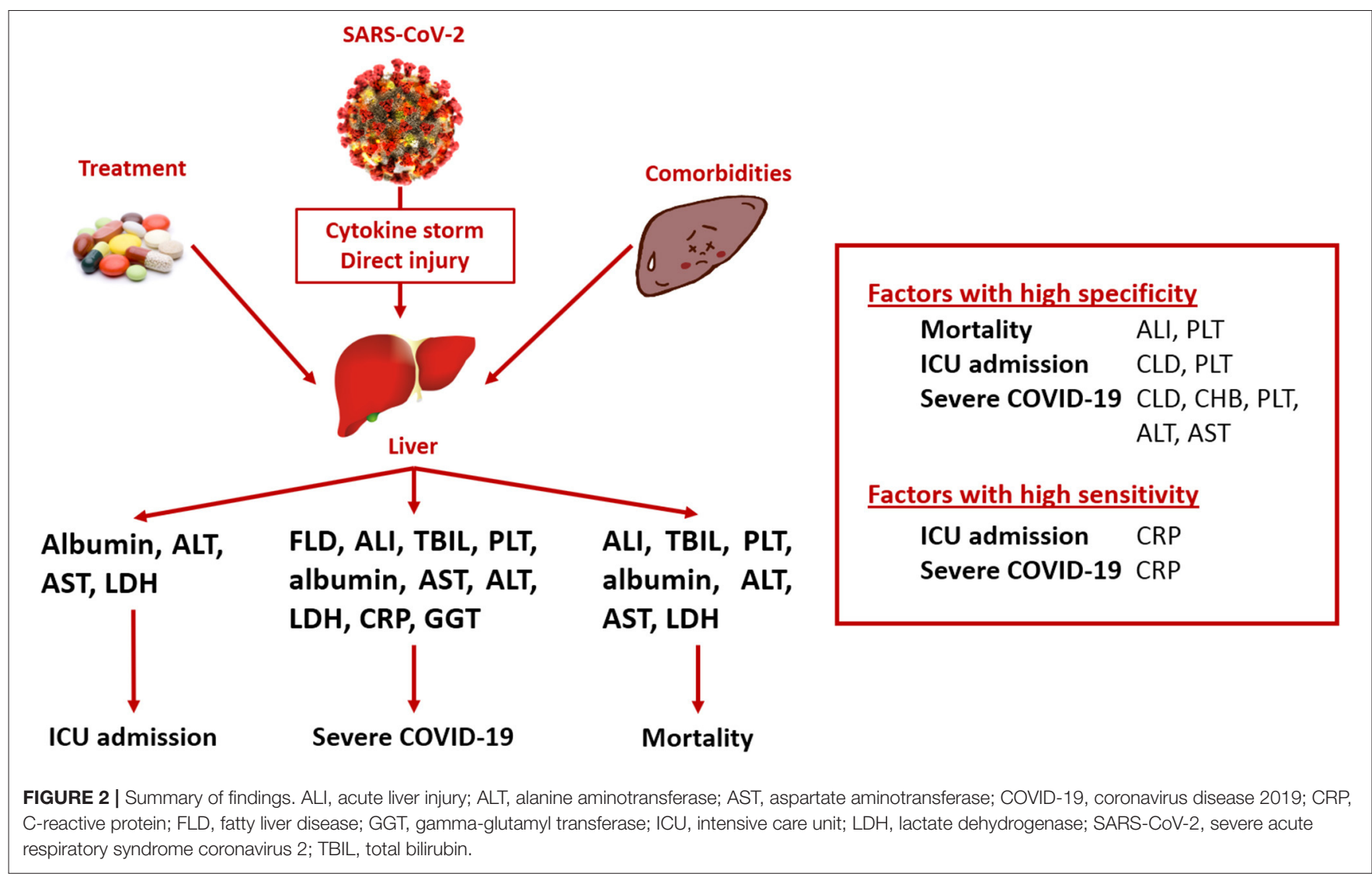

of the investigated outcomes were not uniform among the included reports; to estimate this problem, we applied a modified QUIPS. The cut-off values of laboratory parameters and the definition of liver diseases (Supplementary Tables 6, 7) were also slightly different among articles, causing probably significant heterogeneity in our analysis. However, the different laboratory methodologies among the centers might justify this difference. Furthermore, previous drug treatment before admission of COVID-19 was not investigated. Multivariate analysis was not applied; thus, the investigated prognostic factors should not be regarded as independent risk factors. This all could contribute to the significant heterogeneity in some of our results.

\section{Implication for Practice}

The establishment of a prognostic score assessing the possible outcomes of patients suffering from any liver pathology is needed. This meta-analysis succeeded to identify some factors, with high specificity, which might be a footstone for such a prognostic tool that might be completed by additionally recognized risk factors, for example, elevated absolute white blood cell count, decreased lymphocyte count, and elevated interleukin-6 and serum ferritin concentrations (80). Patients who are affected by the underlying liver pathology might need advanced therapy earlier to avoid undesired clinical outcomes.

\section{Implication for Research}

Based on our results and previously published analyses, further basic research is crucial for a better understanding of the liver injury caused by COVID-19, hepatic comorbidities, and treatment itself.

\section{CONCLUSION}

In conclusion, on-admission platelet count, ALT and AST activities, CRP concentration, and the presence of acute and CLDs predicted the severe course of COVID-19. To highlight, investigating hepatic injury associated by SARS-CoV-2 infection may play an important role in the prediction of mortality and may be used for the establishment of prognostic tools to identify patients with possible poorer outcomes.

\section{DATA AVAILABILITY STATEMENT}

All datasets generated for this study are included in the article/Supplementary Material.

\section{AUTHOR CONTRIBUTIONS}

SV, PJH, NZ, LS, and NV conceived the study. SV, PHe, and GP wrote the protocol. LS and NZ did the literature search. PJH, NV, $\mathrm{ZD}$, and FD screened the records and extracted the data. KJ, MF, 
and SK validated the extracted data. $\mathrm{PHa}$ and $\mathrm{TH}$ assessed the quality of included studies. DN did the statistical analysis. SV, ZS, ZR, and KO prepared the tables. NZ, LS, NV, SV, and PJH wrote the first draft of this manuscript. BE, ZS, GP, and $\mathrm{PHe}$ supervised the manuscript and approved the submitted draft. GP is the guarantor of this paper and, as a hepatologist, provided the team with an expert background. All authors provided critical conceptual input, interpreted the data analysis, and critically revised and approved the final version of the manuscript.

\section{FUNDING}

This study was supported by the Human Resources Development Operational Program Grant (EFOP-362-16-2017-00006),

\section{REFERENCES}

1. Coronavirus Disease (COVID-2019): Situation Report, 113 (2020). Available online at: https:/www.who.int/emergencies/diseases/novel-coronavirus2019/situation-reports/ (accessed May 12, 2020).

2. Wu Z, McGoogan JM. Characteristics of and important lessons from the coronavirus disease 2019 (COVID-19) outbreak in China: summary of a report of 72314 cases from the Chinese Center for Disease Control and Prevention. JAMA. (2020) 323:1239-42. doi: 10.1001/jama.2020.2648

3. Arentz M, Yim E, Klaff L, Lokhandwala S, Riedo FX, Chong M, et al. Characteristics and outcomes of 21 critically ill patients with COVID-19 in Washington State. JAMA. (2020) 323:1612-4. doi: 10.1001/jama.2020.4326

4. Chen R, Liang W, Jiang M, Guan W, Zhan C, Wang T, et al. Risk factors of fatal outcome in hospitalized subjects with coronavirus disease 2019 from a nationwide analysis in China. Chest. (2020) 158:97105. doi: 10.1016/j.chest.2020.04.010

5. Guan W-j, Ni Z-y, Hu Y, Liang W-h, Ou C-q, He J-x, et al. Clinical characteristics of coronavirus disease 2019 in China. N Engl J Med. (2020) 382:1708-20. doi: 10.1056/NEJMoa2002032

6. Zádori N, Váncsa S, Farkas N, Hegyi P, Erőss BJICM. The negative impact of comorbidities on the disease course of COVID-19. Intensive Care Med. (2020) 46:1784-6. doi: 10.1007/s00134-020-06161-9

7. Wu Y, Xu X, Chen Z, Duan J, Hashimoto K, Yang L, et al. Nervous system involvement after infection with COVID-19 and other coronaviruses. Brain Behav Immun. (2020) 87:18-22. doi: 10.1016/j.bbi.2020.03.031

8. Chai X, Hu L, Zhang Y, Han W, Lu Z, Ke A, et al. Specific ACE2 expression in cholangiocytes may cause liver damage after 2019-nCoV infection. BioRxiv [pre print]. (2020). doi: 10.1101/2020.02.03.931766

9. Li YC, Bai WZ, Hashikawa T. The neuroinvasive potential of SARS-CoV2 may play a role in the respiratory failure of COVID-19 patients. J Med Virol. (2020) 92:552-5. doi: 10.1002/jmv.25728

10. Kang Y, Chen T, Mui D, Ferrari V, Jagasia D, Scherrer-Crosbie M, et al. Cardiovascular manifestations and treatment considerations in covid-19. Heart. (2020) 106-1132-41. doi: 10.1136/heartjnl-2020-317056

11. Organization WH. Modes of transmission of virus causing COVID19: implications for IPC precaution recommendations: scientific brief. World Health Organization (2020). Available online at: WHO/2019-nCoV/Sci_Brief/Transmission_modes/2020.2 (accessed May 12, 2020).

12. Xu L, Liu J, Lu M, Yang D, Zheng X. Liver injury during highly pathogenic human coronavirus infections. Liver Int. (2020) 40:9981004. doi: 10.1111/liv.14435

13. Moher D, Liberati A, Tetzlaff J, Altman DG. Preferred reporting items for systematic reviews and meta-analyses: the PRISMA statement. BMJ. (2009) 339:b2535. doi: 10.1136/bmj.b2535

14. Zu ZY, Jiang MD, Xu PP, Chen W, Ni QQ, Lu GM, et al. Coronavirus disease 2019 (COVID-19): a perspective from China. Radiology. (2020) 296:E15E25. doi: 10.1148/radiol.2020200490 co-financed by the European Union (European Regional Development Fund) within the framework of the Széchenyi 2020 Program. The sponsor or the funders of the study had no role in the study design, data collection, data analysis, data interpretation, or writing of the report. The corresponding author had full access to all the data in the study and had final responsibility for the decision to submit for publication.

\section{SUPPLEMENTARY MATERIAL}

The Supplementary Material for this article can be found online at: https://www.frontiersin.org/articles/10.3389/fmed. 2020.572115/full\#supplementary-material

15. Higgins JP, Thompson SG, Deeks JJ, Altman DG. Measuring inconsistency in meta-analyses. BMJ. (2003) 327:557-60. doi: 10.1136/bmj.327.7414.557

16. Egger M, Smith GD, Schneider M, Minder C. Bias in metaanalysis detected by a simple, graphical test. BMJ. (1997) 315:629-34. doi: 10.1136/bmj.315.7109.629

17. Deeks JJ, Higgins JP, Altman DG, interventions CSMGJChfsro. Analysing data and undertaking meta-analyses. (2019) :24184. doi: 10.1002/9781119536604.ch10

18. Hayden JA, van der Windt DA, Cartwright JL, Côté P, Bombardier C. Assessing bias in studies of prognostic factors. Ann Intern Med. (2013) 158:280-6. doi: 10.7326/0003-4819-158-4-201302190-00009

19. Cai Q, Huang D, Ou P, Yu H, Zhu Z, Xia Z, et al. COVID-19 in a designated infectious diseases hospital outside Hubei Province, China. Allergy. (2020) 75:1742-52. doi: 10.1101/2020.02.17.200 24018

20. Cai Q, Huang D, Yu H, Zhu Z, Xia Z, Su Y, et al. COVID-19: Abnormal liver function tests. J Hepatol. (2020) 73:566-74. doi: 10.1016/j.jhep.2020.04.006

21. Cao J, Tu W-J, Cheng W, Yu L, Liu Y-K, Hu X, et al. Clinical Features and short-term outcomes of 102 patients with corona virus disease 2019 in Wuhan, China. Clin Infect Dis. (2020) 71:748-55. doi: 10.1093/cid/ciaa243

22. Chen G, Wu D, Guo W, Cao Y, Huang D, Wang H, et al. Clinical and immunological features of severe and moderate coronavirus disease 2019. J Clin Invest. (2020) 130:2620-9. doi: 10.1172/JCI137244

23. Chen T, Wu D, Chen H, Yan W, Yang D, Chen G, et al. Clinical characteristics of 113 deceased patients with coronavirus disease 2019: retrospective study. BMJ. (2020) 368:m1091. doi: 10.1136/bmj.m1091

24. Chen T, Dai Z, Mo P, Li X, Ma Z, Song S, et al. Clinical characteristics and outcomes of older patients with coronavirus disease 2019 (COVID-19) in Wuhan, China (2019) : a single-centered, retrospective study. J Gerontol. (2020) 75:1788-95. doi: 10.1093/gerona/glaa089

25. Chen X, Zhao B, Qu Y, Chen Y, Xiong J, Feng Y, et al. Detectable serum SARSCoV-2 viral load (RNAaemia) is closely correlated with drastically elevated interleukin 6 (IL-6) level in critically ill COVID-19 patients. Clin Infect Dis. (2020). doi: 10.1101/2020.02.29.20029520

26. Colombi D, Bodini FC, Petrini M, Maffi G, Morelli N, Milanese G, et al. Wellaerated lung on admitting chest CT to predict adverse outcome in COVID19 pneumonia. Radiology. (2020) 296:E86-E96. doi: 10.1148/radiol.2020 201433

27. Du RH, Liu LM, Yin W, Wang W, Guan LL, Yuan ML, et al. Hospitalization and critical care of 109 decedents with COVID-19 pneumonia in Wuhan, China. Ann Am Thorac Soc. (2020) 17:83946. doi: 10.1513/AnnalsATS.202003-225OC

28. Fan BE, Chong VCL, Chan SSW, Lim GH, Lim KGE, Tan GB, et al. Hematologic parameters in patients with COVID-19 infection. Am J Hematol. (2020) 95:E131-E4. doi: 10.1002/ajh.25774

29. Fan Z, Chen L, Li J, Cheng X, Yang J, Tian C, et al. Clinical features of COVID-19-related liver damage. Clin Gastroenterol Hepatol. (2020) 18:15616. doi: $10.1016 /$ j.cgh.2020.04.002 
30. Feng Y, Ling Y, Bai T, Xie Y, Huang J, Li J, et al. COVID-19 with different severity: a multi-center study of clinical features. Am J Respir Crit Care Med. (2020) 201:1380-8. doi: 10.1164/rccm.202002-0445OC

31. Goyal P, Choi JJ, Pinheiro LC, Schenck EJ, Chen R, Jabri A, et al. Clinical characteristics of Covid-19 in New York City. N Engl J Med. (2020) 382:23724. doi: 10.1056/NEJMc2010419

32. Grein J, Ohmagari N, Shin D, Diaz G, Asperges E, Castagna A, et al. Compassionate Use of remdesivir for patients with severe Covid-19. N Engl J Med. (2020) 382:2327-36. doi: 10.1056/NEJMoa2007016

33. Guan W-j, Liang W-h, Zhao Y, Liang H-r, Chen Z-s, Li Y-m, et al. Comorbidity and its impact on 1590 patients with Covid-19 in China: a nationwide analysis. Eur Respir J. (2020) 55:2000547. doi: 10.1183/13993003.01227-2020

34. Huang C, Wang Y, Li X, Ren L, Zhao J, Hu Y, et al. Clinical features of patients infected with 2019 novel coronavirus in Wuhan, China. Lancet. (2020) 395:497-506. doi: 10.1016/S0140-6736(20)30183-5

35. Ji D, Qin E, Xu J, Zhang D, Cheng G, Wang Y, et al. Non-alcoholic fatty liver diseases in patients with COVID-19: retrospective study. J Hepatol. (2020) 73:451-3. doi: 10.1016/j.jhep.2020.03.044

36. Ji D, Zhang D, Xu J, Chen Z, Yang T, Zhao P, et al. Prediction for progression risk in patients with COVID-19 pneumonia: the CALL Score. Clin Infect Dis. (2020) 71:1363-9. doi: 10.1093/cid/ciaa414

37. Li X, Xu S, Yu M, Wang K, Tao Y, Zhou Y, et al. Risk factors for severity and mortality in adult COVID-19 inpatients in Wuhan. J Allergy Clin Immunol. (2020) 146:110-18. doi: 10.1016/j.jaci.2020.04.006

38. Liu Y, Sun W, Guo Y, Chen L, Zhang L, Zhao S, et al. Association between platelet parameters and mortality in coronavirus disease 2019: Retrospective cohort study. Platelets. (2020) 31:490-6. doi: 10.1080/09537104.2020.1754383

39. Qi X, Liu C, Jiang Z, Gu Y, Zhang G, Shao C, et al. Multicenter analysis of clinical characteristics and outcome of COVID-19 patients with liver injury. $J$ Hepatol. (2020) 73:455-8. doi: 10.1016/j.jhep.2020.04.010

40. Qian ZP, Mei X, Zhang YY, Zou Y, Zhang ZG, Zhu H, et al. [Analysis of baseline liver biochemical parameters in 324 cases with novel coronavirus pneumonia in Shanghai area]. Zhonghua Gan Zang Bing Za Zhi. (2020) 28:229-33. doi: 10.3760/cma.j.cn501113-20200229-00076

41. Qin C, Zhou L, Hu Z, Zhang S, Yang S, Tao Y, et al. Dysregulation of immune response in patients with COVID-19 in Wuhan, China. Clin Infect Dis. (2020) 71:762-8. doi: $10.1093 / \mathrm{cid} / \mathrm{ciaa} 248$

42. Richardson S, Hirsch JS, Narasimhan M, Crawford JM, McGinn T, Davidson KW, et al. Presenting characteristics, comorbidities, and outcomes among 5700 patients hospitalized with COVID-19 in the New York City Area. JAMA. (2020) 323:2052-9. doi: 10.1001/jama.2020.6775

43. Ruan Q, Yang K, Wang W, Jiang L, Song J. Clinical predictors of mortality due to COVID-19 based on an analysis of data of 150 patients from Wuhan, China. Intensive Care Med. (2020) 46:846-8. doi: 10.1007/s00134-020-05991-x

44. Shen L, Li S, Zhu Y, Zhao J, Tang X, Li H, et al. Clinical and laboratoryderived parameters of 119 hospitalized patients with coronavirus disease 2019 in Xiangyang, Hubei Province, China. J Infect. (2020) 81:14778. doi: 10.1016/j.jinf.2020.03.038

45. Shi Y, Yu X, Zhao H, Wang H, Zhao R, Sheng J. Host susceptibility to severe COVID-19 and establishment of a host risk score: findings of 487 cases outside Wuhan. Crit Care. (2020) 24:108. doi: 10.1186/s13054-020-2833-7

46. To KK-W, Tsang OT-Y, Leung W-S, Tam AR, Wu T-C, Lung DC, et al. Temporal profiles of viral load in posterior oropharyngeal saliva samples and serum antibody responses during infection by SARS-CoV2: an observational cohort study. Lancet Infect Dis. (2020) 20:56574. doi: 10.1016/S1473-3099(20)30196-1

47. Tu W-J, Cao J, Yu L, Hu X, Liu Q. Clinicolaboratory study of 25 fatal cases of COVID-19 in Wuhan. Intensive Care Med. (2020) 46:111720. doi: 10.1007/s00134-020-06023-4

48. Wan S, Xiang Y, Fang W, Zheng Y, Li B, Hu Y, et al. Clinical features and treatment of COVID-19 patients in northeast Chongqing. J Med Virol. (2020) 92:797-806. doi: 10.1002/jmv.25783

49. Wan S, Yi Q, Fan S, Lv J, Zhang X, Guo L, et al. Relationships among lymphocyte subsets, cytokines, and the pulmonary inflammation index in coronavirus (COVID-19) infected patients. Br J Haematol. (2020) 189:42837. doi: 10.1111/bjh.16659
50. Wang L, He W, Yu X, Hu D, Bao M, Liu H, et al. Coronavirus disease 2019 in elderly patients: characteristics and prognostic factors based on 4-week follow-up. J Infect. (2020) 80:639-45. doi: 10.1016/j.jinf.2020.03.019

51. Wang Y, Liu Y, Liu L, Wang X, Luo N, Li L. Clinical outcomes in 55 patients with severe acute respiratory syndrome coronavirus 2 who were asymptomatic at hospital admission in Shenzhen, China. J Infect Dis. (2020) 221:1770-4. doi: 10.1093/infdis/jiaa119

52. Wang Z, Yang B, Li Q, Wen L, Zhang R. Clinical Features of 69 Cases With Coronavirus Disease 2019 in Wuhan, China. Clin Infect Dis. (2020) 71:769-77. doi: 10.1093/cid/ciaa272

53. Wu J, Li W, Shi X, Chen Z, Jiang B, Liu J, et al. Early antiviral treatment contributes to alleviate the severity and improve the prognosis of patients with novel coronavirus disease (COVID-19). J Intern Med. (2020) 288:12838. doi: 10.1111/joim.13063

54. Yang A-P, Liu J-P, Tao W-Q, Li H-M. The diagnostic and predictive role of NLR, d-NLR and PLR in COVID-19 patients. Int Immunopharmacol. (2020) 84:106504. doi: 10.1016/j.intimp.2020.106504

55. Yang X, Yang Q, Wang Y, Wu Y, Xu J, Yu Y, et al. Thrombocytopenia and its association with mortality in patients with COVID-19. J Thromb Haemost. (2020) 18:1469-72. doi: 10.1111/jth.14848

56. Yang X, Yu Y, Xu J, Shu H, Xia Ja, Liu H, et al. Clinical course and outcomes of critically ill patients with SARS-CoV-2 pneumonia in Wuhan, China: a single-centered, retrospective, observational study. Lancet Resp Med. (2020) 8:475-81. doi: 10.1016/S2213-2600(20)30079-5

57. Zhang G, Hu C, Luo L, Fang F, Chen Y, Li J, et al. Clinical features and shortterm outcomes of 221 patients with COVID-19 in Wuhan, China. J Clin Virol. (2020) 127:104364. doi: 10.1016/j.jcv.2020.104364

58. Zhang J, Wang X, Jia X, Li J, Hu K, Chen G, et al. Risk factors for disease severity, unimprovement, and mortality in COVID-19 patients in Wuhan, China. Clin Microbiol Infect. (2020) 26:767-72. doi: 10.1016/j.cmi.2020.04.012

59. Zhang J-j, Dong X, Cao Y-y, Yuan Y-d, Yang Y-b, Yan Y-q, et al. Clinical characteristics of 140 patients infected with SARS-CoV-2 in Wuhan, China. Allergy. (2020) 75:1730-41. doi: 10.1111/all.14238

60. Zhang R, Ouyang H, Fu L, Wang S, Han J, Huang K, et al. CT features of SARS-CoV-2 pneumonia according to clinical presentation: a retrospective analysis of 120 consecutive patients from Wuhan city. Eur Radiol. (2020) 30:4417-26. doi: 10.1007/s00330-020-06854-1

61. Zhang Y, Zheng L, Liu L, Zhao M, Xiao J, Zhao Q. Liver impairment in COVID-19 patients: a retrospective analysis of 115 cases from a single center in Wuhan city, China. Liver Int. (2020) 40:2095-103. doi: 10.1111/liv.14455

62. Zheng F, Tang W, Li H, Huang YX, Xie YL, Zhou ZG. Clinical characteristics of 161 cases of corona virus disease 2019 (COVID-19) in Changsha. Eur Rev Med Pharmacol Sci. (2020) 24:3404-10. doi: 10.26355/eurrev_202003_20711

63. Zheng S, Fan J, Yu F, Feng B, Lou B, Zou Q, et al. Viral load dynamics and disease severity in patients infected with SARS-CoV-2 in Zhejiang province, China, January-March 2020: retrospective cohort study. BMJ. (2020) 369:m1443. doi: 10.1136/bmj.m1443

64. Zhou F, Yu T, Du R, Fan G, Liu Y, Liu Z, et al. Clinical course and risk factors for mortality of adult inpatients with COVID-19 in Wuhan, China: a retrospective cohort study. Lancet. (2020) 395:105462. doi: 10.1016/S0140-6736(20)30566-3

65. Zhou W, Liu Y, Tian D, Wang C, Wang S, Cheng J, et al. Potential benefits of precise corticosteroids therapy for severe 2019-nCoV pneumonia. Signal Transduct Target Ther. (2020) 5:18. doi: 10.1038/s41392-020-0127-9

66. Zhou Y, Han T, Chen J, Hou C, Hua L, He S, et al. Clinical and autoimmune characteristics of severe and critical cases with COVID-19. Clin Transl Sci. (2020). doi: 10.1111/cts.12805

67. Lippi G, de Oliveira MHS, Henry BM. Chronic liver disease is not associated with severity or mortality in Coronavirus disease 2019 (COVID-19): a pooled analysis. Eur J Gastroen Hepat. (2020). doi: 10.1097/MEG.0000000000001742

68. Gacouin A, Locufier M, Uhel F, Letheulle J, Bouju P, Fillatre P, et al. Liver cirrhosis is independently associated with 90-day mortality in ARDS patients. Shock. (2016) 45:16-21. doi: 10.1097/SHK.0000000000000487

69. Albillos A, Lario M, Álvarez-Mon M. Cirrhosis-associated immune dysfunction: distinctive features and clinical relevance. J Hepatol. (2014) 61:1385-96. doi: 10.1016/j.jhep.2014.08.010 
70. Mantovani A, Beatrice G, Dalbeni A. Coronavirus disease 2019 (COVID19) and prevalence of chronic liver disease: a meta-analysis. Liver Int. (2020) 65:235-6. doi: 10.1007/s00038-020-01369-4

71. Yadav DK, Singh A, Zhang Q, Bai X, Zhang W, Yadav RK, et al. Involvement of liver in COVID-19: systematic review and meta-analysis. Gut. (2020). doi: 10.1136/gutjnl-2020-322072

72. Kumar-M P, Mishra S, Jha DK, Shukla J, Choudhury A, Mohindra $\mathrm{R}$, et al. Coronavirus disease (COVID-19) and the liver: a comprehensive systematic review and meta-analysis. Hepatol Int. (2020) 14:711-22. doi: 10.1007/s12072-020-10071-9

73. Mao R, Qiu Y, He J-S, Tan J-Y, Li X-H, Liang J, et al. Manifestations and prognosis of gastrointestinal and liver involvement in patients with COVID19: a systematic review and meta-analysis. Lancet Gastroenterol. (2020) 5:6678. doi: 10.1016/S2468-1253(20)30126-6

74. Zhou Y-J, Zheng KI, Wang X-B, Yan H-D, Sun Q-F, Pan K-H, et al. Younger patients with MAFLD are at increased risk of severe COVID19 illness: a multicenter preliminary analysis. J Hepatol. (2020) 73:71921. doi: 10.1016/j.jhep.2020.04.027

75. Parohan M, Yaghoubi S, Seraj A. Liver injury is associated with severe Coronavirus disease 2019 (COVID-19) infection: a systematic review and meta-analysis of retrospective studies. medRxiv [pre print]. (2020). doi: 10.1101/2020.04.09.20056242

76. Zippi M, Fiorino S, Occhigrossi G, Hong W. Hypertransaminasemia in the course of infection with SARS-CoV-2: incidence and pathogenetic hypothesis. World J Clin Cases. (2020) 8:1385-90. doi: 10.12998/wjcc.v8.i 8.1385
77. Xu Z, Shi L, Wang Y, Zhang J, Huang L, Zhang C, et al. Pathological findings of COVID-19 associated with acute respiratory distress syndrome. Lancet Resp Med. (2020) 8:420-2. doi: 10.1016/S2213-2600(20)30076-X

78. Terpos E, Ntanasis-Stathopoulos I, Elalamy I, Kastritis E, Sergentanis TN, Politou M, et al. Hematological findings and complications of COVID-19. Am J Hematol. (2020) 95:834-47. doi: 10.1002/ajh.25829

79. Sonzogni A, Previtali G, Seghezzi M, Grazia Alessio M, Gianatti A, Licini L, et al. Liver histopathology in severe COVID 19 respiratory failure is suggestive of vascular alterations. Liver Int. (2020) 40:2110-6. doi: 10.1111/liv.14601

80. Henry BM, De Oliveira MHS, Benoit S, Plebani M, Lippi G. Hematologic, biochemical and immune biomarker abnormalities associated with severe illness and mortality in coronavirus disease 2019 (COVID-19): a metaanalysis. Clin Chem Lab Med. (2020) 58:1021-8. doi: 10.1515/cclm-2020-0369

Conflict of Interest: The authors declare that the research was conducted in the absence of any commercial or financial relationships that could be construed as a potential conflict of interest.

Copyright (c) 2020 Váncsa, Hegyi, Zádori, Szakó, Vörhendi, Ocskay, Földi, Dembrovszky, Dömötör, Jánosi, Rakonczay, Hartmann, Horváth, Eröss, Kiss, Szakács, Németh, Hegyi and Pár. This is an open-access article distributed under the terms of the Creative Commons Attribution License (CC BY). The use, distribution or reproduction in other forums is permitted, provided the original author(s) and the copyright owner(s) are credited and that the original publication in this journal is cited, in accordance with accepted academic practice. No use, distribution or reproduction is permitted which does not comply with these terms. 